\title{
L-Statistical Analysis of Sound Signal Acquired from Pulse Mode Laser Welding for Characterising Weld Geometry
}

\author{
M. F. M. Yusof ${ }^{1,2 *}$, M. Ishak ${ }^{1}$ and M. F. Ghazali ${ }^{2}$ \\ ${ }^{1}$ Joining and Welding Research Group \\ ${ }^{2}$ Advanced Structural Integrity and Vibration Research Group \\ Faculty of Mechanical Engineering, Universiti Malaysia Pahang \\ 26600 Pekan, Pahang, Malaysia, \\ *Email: fadhlan@ump.edu.my
}

\begin{abstract}
Many ongoing studies have proven that statistical features extracted from the acquired sound during a laser welding process significantly yield some pictures on the weld condition, including weld geometry. However, a considerable amount of studies has underlined the use of common statistical features in which they are restricted to some limitations when dealing with non-stationary random sound signal. In the present study, the main aim is to study the correlation between the L-statistical features trend of the sound amplitude distribution with respect to the change in weld geometry during pulse mode laser welding compared to common statistical features. In an attempt to achieve this goal, a pulse mode laser welding was subjected to 22MnB5 boron steel with variations in the peak power, pulse width, and focal length. Meanwhile, the sound signal was acquired during the process, with standard deviation, interdecile range, mean absolute deviation, L-Cv (scale), and L-kurtosis extracted from the analysis. The degree of correlation between these statistical features and weld geometry was compared from the R-square value. According to the reported results, L-kurtosis yielded the strongest correlation with both weld penetration depth and bead width compared to the remaining five statistical features. This showed that the use of L-statistical features was significant to improve the correlation between sound signals and weld geometry.
\end{abstract}

Keywords: Pulse mode laser welding; sound signal; statistical features; L-statistic.

\section{INTRODUCTION}

Since the past few decades, the use of laser welding has started to become more popular due to its benefit in providing weld products with small heat-affected zone, esthetic appearance, less post-weld machining process, and high production rate [1]. Eventually, a significant number of studies pertaining to the optimisation of laser welding process have been reported in the recent years [2-8]. In most industries, there is no tolerance for the presence of defects as they can degrade the strength of welded products. Defects, such as incomplete penetration are some of the types of defect that commonly occur and cause a great concern. Therefore, many researchers suggest that a robust monitoring method for the process is essential because it can promote greater control during the process [9]. Over many years, numerous methods for monitoring laser welding have been studied, inclusive of electrical, thermal, optical, and acoustic methods. Among these methods, the acoustic sound method has received attention recently due to its low cost, simplicity, high responsible speed, and convenient features [10-12]. 
Until recently, many studies have been done to gain a deeper understanding on how the acquired sound behaviour changes from different weld geometries. In most of the cases, sound behaviour is determined by statistical or signal features extracted from the acquired time series sound signal. In earlier research by Duly and Mao [13] back in 1994, the behaviour of acoustic signal from different depths of penetration in Aluminium 1100 was studied based on its spectral amplitude features. The work revealed that the peak from $9 \mathrm{kHz}$ to $10 \mathrm{kHz}$ was found to be increasing in its amplitude simultaneously with gaining laser intensity, which concurrently increased the depth of penetration. Comparable work has been reported by Farson et al. [14] in which the experiment was done on 304 stainless steel plates. Unlike the previous work, the spectral energy in the study was determined instead of amplitude. By applying short-time Fourier Transform to the acquired sound signal, the significant range was recorded to be within $1 \mathrm{kHz}$ to $2 \mathrm{kHz}$, whereas its energy dropped when insufficient penetration was detected. A recent study by Huang and Kovacevic [15] have conversely demonstrated the use of both multiple regression and artificial neural network to characterise the weld penetration from the acquired sound. The research has uniquely demonstrated spectral subtraction method to diminish the influence of noise in the analysis. Furthermore, sound pressure deviation (SPD) and band power (BP) have been introduced as the signal or statistical features to characterise the depth of penetration. The work has successfully demonstrated that the depth of penetration can be estimated from the acquired sound signal.

Apart from the qualitative comparison and quantitative characterisation of the statistical or signal features from different weld geometries, previous studies have also involved the classification of weld quality according to its geometry from the sound signal features. In the extended study by Farson et al. [16], the investigation was done in a broader range of power and travel speed. In contrast with their preceding work, the root mean square (RMS) of the acquired sound has been used as a feature to identify whether the penetration status feels under-full, moderately full, or otherwise partial penetration class. Another research [17] extended the scope to include high power or keyhole welding. Supported by measured optical charged particle data, the depth of penetration status can be classified into full penetration, overheat penetration, and half-penetration. Another major study by Huang and Kovacevic [10] allowed the classification of half and full-penetration weld through the analysis of both time and frequency domain signal characteristics. As an observation made regarding the captured time domain, it was reported that the overall SPD aligned with the growing penetration depth. Meanwhile, the $\mathrm{BP}$ of frequency spectrum from $500 \mathrm{~Hz}$ to $1500 \mathrm{~Hz}$ is large for full penetration compared to half penetration.

As established from a wide variety of studies, it can be summarised that the statistical or signal features extracted from sound acquired via laser welding process can probably yield significant information on the weld geometry. However, a considerable amount of studies only emphasised on the use of acoustic method for continuous laser welding mode. Until now, far too little attention has been paid to the study of sound behaviour during pulse laser welding. It is anticipated that the identification of appropriate statistical features for sound emitted from the pulse mode laser welding to be more challenging. This is due to the fact that the process produces transient signal, which is considered to be non-stationary random. Moreover, it is essential to look into another type of statistical feature in an attempt to improve the error in characterising weld geometry during pulse mode laser welding.

In this work, the aim was to study the correlation between the trends of Lstatistical features for sound amplitude distribution with respect to the change in weld 
geometry during pulse mode laser welding. The analysis was divided into measurement of dispersion and shape of the amplitude distribution in order to identify which feature yielded a significant relation with the weld geometry. In general, standard deviation, interdecile range, and mean absolute deviation were the selected parameters to signify the dispersion of sound amplitude distribution. Meanwhile, kurtosis, L-Cv (scale) and Lkurtosis were the parameters representing its shape. Specifically, standard deviation, interquartile range, mean absolute deviation and kurtosis were analysed in this study as they have been demonstrated to significantly aid in monitoring weld conditions, including weld geometry, in many studies inclusive of other types of welding processes [18-22].

Meanwhile, L-scale and L-kurtosis were analysed in an attempt to study how they could avoid the drawbacks arising from the influence of sample variation and local extreme or outliers, as verified in another discipline of study [23-25]. As a comparison, the most significant feature was determined from the regression analysis result.

\section{METHODS AND ANALYSIS}

The experiment is set up as illustrated in Figure 1. In this experiment, bead-on-plate laser welding process was done on $22 \mathrm{MnB} 5$ boron steel plate with a thickness of $1.8 \mathrm{~mm}$. According to previous studies [2, 26, 27], focal length, laser peak power, and pulse width were the major parameters that could influence the depth of penetration. Therefore, in this study, the peak power and pulse width are set to be varied according to Table 1. Meanwhile, the focal length varied from $-5 \mathrm{~mm}$ to $+5 \mathrm{~mm}$ defocused, while the angle used in this experiment was fixed to 50. The angle selection was made to decrease the amount of back-reflected laser during the welding process. For each of the parameter set, the experiment was repeated five times. During the welding process, the specimen moved at a constant speed of $1.5 \mathrm{~mm} / \mathrm{s}$, while the argon gas with the flow rate of $15 \mathrm{~L} / \mathrm{min}$ was used as shielding gas.

In the meantime, the emitted sound was acquired using PCB piezotronics freefield microphone, which was capable of capturing the flat response signal between $20 \mathrm{~Hz}$ and $10000 \mathrm{~Hz}$. Prior to the acquisition process, signal-to-noise ratio mapping determination was conducted as depicted in Figure 2. Results showed that the highest signal-to-noise ratio was recorded at the location between $20 \mathrm{~cm}$ and $25 \mathrm{~cm}, 30 \mathrm{~cm}$ and $35 \mathrm{~cm}$, and between $150^{\circ}$ and $450^{\circ}$ angle from the laser spot. Furthermore, by considering the effect of spatter if the microphone were located too close to the laser spot and low sound pressure level if placed too far, the microphone was located at $25 \mathrm{~cm}$ and 300 degrees angle from the laser spot. Meanwhile, the sampling rate was set to be 25.6 $\mathrm{kSample/s}$. The decision was made according to the Nyquist theorem. The acquired signal from the microphone was converted into digital form using NI9234 A/D converter before undergoing statistical features extraction using a digital processor. 


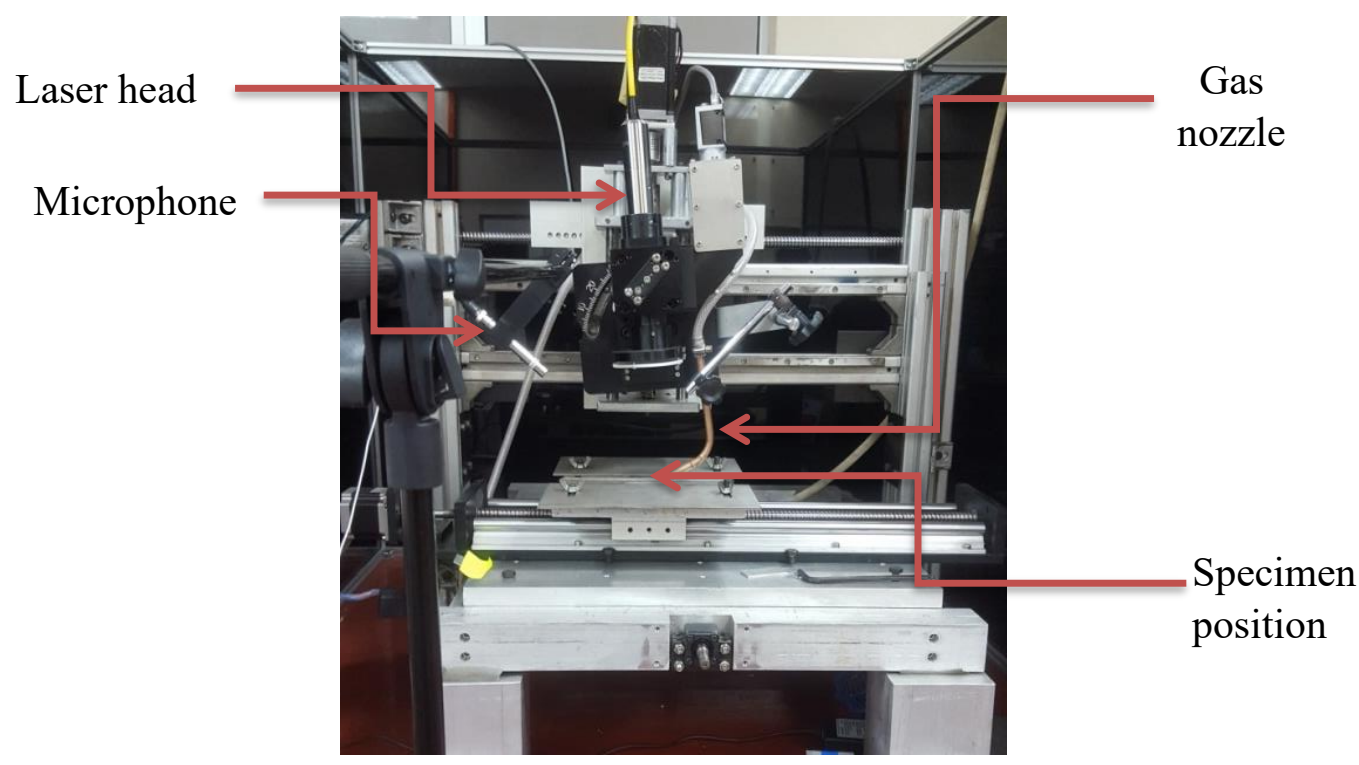

Figure 1. Laser experiment and data acquisition setup.

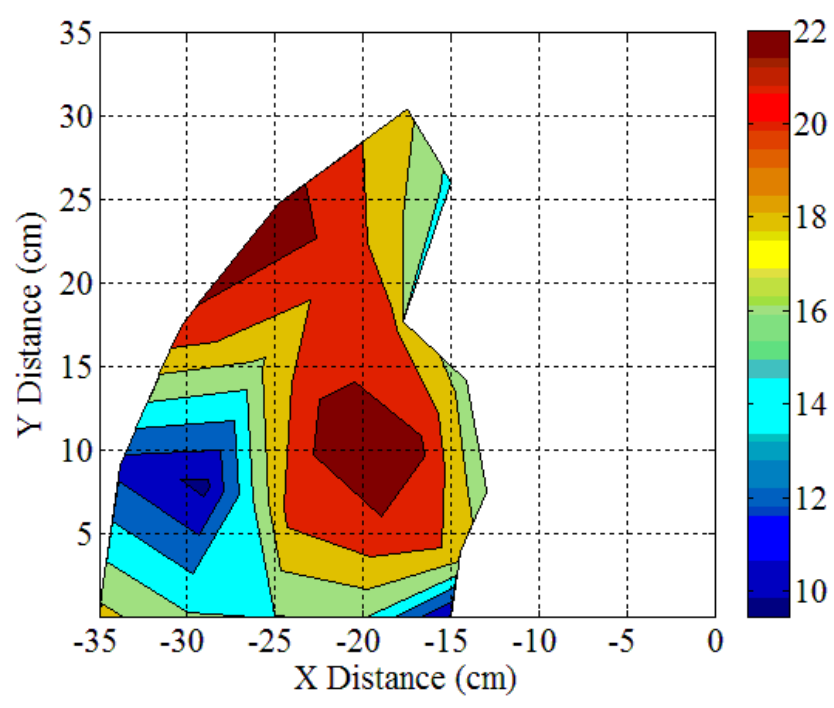

Figure 2. Signal-to-noise ratio mapping on the left side of laser machine.

Table 1. Parameter variations for pulse laser welding process

\begin{tabular}{lccccc}
\hline $\begin{array}{l}\text { Pulse width } \\
(\mathrm{ms})\end{array}$ & $\begin{array}{c}\text { Laser Peak } \\
\text { Power (W) }\end{array}$ & $\begin{array}{c}\text { Pulse width } \\
(\mathrm{ms})\end{array}$ & $\begin{array}{c}\text { Laser Peak } \\
\text { Power (W) }\end{array}$ & $\begin{array}{c}\text { Pulse width } \\
(\mathrm{ms})\end{array}$ & $\begin{array}{c}\text { Laser Peak } \\
\text { Power (W) }\end{array}$ \\
\hline & 400 & & 400 & & 400 \\
& 600 & & 600 & & 600 \\
2 & 800 & 4 & 800 & 6 & 800 \\
& 1000 & & 1000 & & 1000 \\
& 1200 & & 1200 & & 1200 \\
& 1400 & & 1400 & & 1400 \\
\hline
\end{tabular}




\section{Statistical Analysis}

Literally, the time series of sound signal $x(t)$ could be assumed as the dataset with $N$ number of samples. $(i=1,2,3, \ldots, N)$. In time domain, signal $x(i)$ represents the amplitude at the specific time. Thus, by extracting the statistical feature, the trend of amplitude distribution could be observed to characterise the signal.

Basically, the amplitude distribution could be characterised by its dispersion and shape. In this study, the standard deviation, interdecile range and mean absolute deviation represented the dispersion measures for amplitude distribution. Those statistical parameters were determined by using Equations (1), (2) and (3), respectively, where N, $\mathrm{xi}$, and $\mu$ in Equation (1) and Equation (3) represent the total number of data point, the ith data point and mean of the acquired sound signal.

Std Dev $=\sqrt{\frac{\text { i=l }_{i=1}^{N}\left(x_{i}-\mu\right)}{N}}$

Interdecile range $=90$ th percentile-10th percentile

Mean absolute deviation $=\frac{1}{n} \sum_{i=1}^{N} / x_{i}-\mu /$

Furthermore, the shape of the amplitude distribution was measured by conventional statistical moment and L-moment. In many studies involving monitoring welding process [18-21], the shape of distribution is determined from the 3rd and 4th order moments namely, skewness and kurtosis, respectively. In this study, kurtosis was selected for analysis due to the nature of the pulse mode laser welding, which produced the transient sound. It was determined by the following equation, where $\mathrm{i}$ and $\mathrm{N}$ were ith data point and number of sample, respectively.

$\operatorname{Kurt}(X)=\frac{1}{N} \sum_{i=1}^{N}\left(\frac{x_{i}^{-} \mu}{\sigma}\right)^{4}$

In order to avoid the drawback arising from the influence of sample variation and local extreme or outliers, the L-moment as proposed by Hosking [28] was also analysed in this study. More specifically, the L-Cv (scale) was determined to observe the variation of the sound amplitude distribution, whereby its value could be determined using the following equation.

$L-C v($ Scale $)=\frac{2\left(\frac{1}{N} \sum_{i=2}^{N} x_{i}\left[\frac{i-1}{N-1}\right]\right)-\left(\frac{1}{N} \sum_{i=1}^{N} x_{i}\right)}{\left(\frac{I}{N} \sum_{i=1}^{N} x_{i}\right.}$

$\mathrm{L}-\mathrm{Cv}$ commonly gives the measures of variability in amplitude distribution in which it is also correlated with the skewness of the amplitude distribution [29]. Meanwhile, in this work, the trend of L-kurtosis as shown in Equation (6) was observed.

$L-K u r t=\frac{20\left(\frac{1}{N} \sum_{i=4}^{N} x_{i}\left[\frac{(i-1)(i-2)(i-3)}{(N-1)(N-2)(N-3)}\right]\right)-30\left(\frac{1}{N} \sum_{i=3}^{N} x_{i}\left[\frac{(i-1)(i-2)}{(N-1)(N-2)}\right]\right)+12\left(\frac{1}{N} \sum_{i=2}^{N} x_{i}\left[\frac{(i-1)}{(N-1)}\right]\right)-\left(\frac{1}{N} \sum_{i=1}^{N} x_{i}\right)}{2\left(\frac{l}{n} \sum_{i=2}^{N} x_{i}\left[\frac{i-1}{N-1}\right]\right)-\left(\frac{l}{N} \sum_{i=1}^{N} x_{i}\right)}$ 


\section{RESULTS AND DISCUSSION}

\section{Effect of Weld Parameters on Weld Geometry}

The introduction part emphasised that the aim of this work was to study the correlation between the statistical features of sound amplitude distribution with weld geometry. Meanwhile, the disparities of weld geometry were obtained from different peak power, pulse width, and focal length, which were varied during the experiment. Therefore, it was important to observe the influence of these parameters towards the weld geometry prior to the correlation analysis.

Figure 3 and 4 depict the variations of weld geometry with respect to the change in peak power for the welding process, with different pulse widths and focal lengths. There were several similar trends that could be listed from the case of welding process with different focal lengths. At the outset, it was clear that for all focal lengths, the depth of penetration and bead width increased the values with the increment in peak power and pulse width. The trend for the penetration depth was almost directly linear compared to the bead width. However, the rate of depth change with respect to the increment in peak power was found to slightly increase after reaching $800 \mathrm{~W}$. On the other hand, the rate of bead width increment was found to be reduced when the peak power exceeded $800 \mathrm{~W}$. In order to investigate the reason behind this phenomenon, the trend of aspect ratio in response to the change in peak power is depicted in Figure 5.

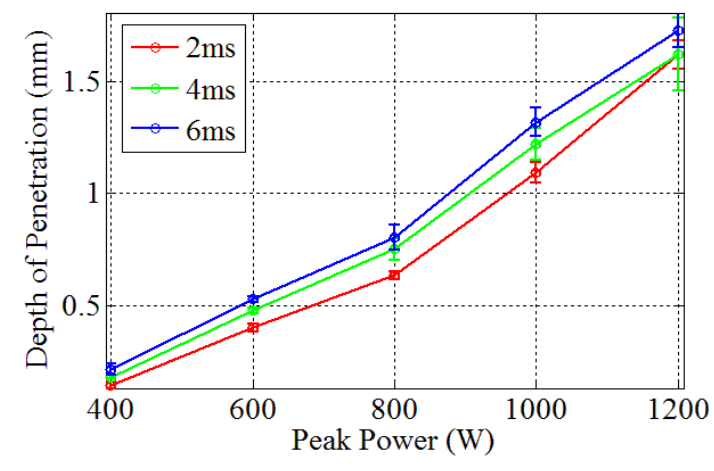

(a)

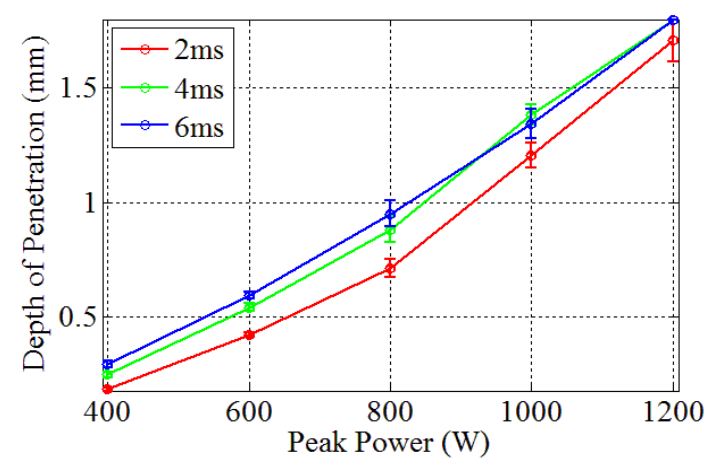

(b)

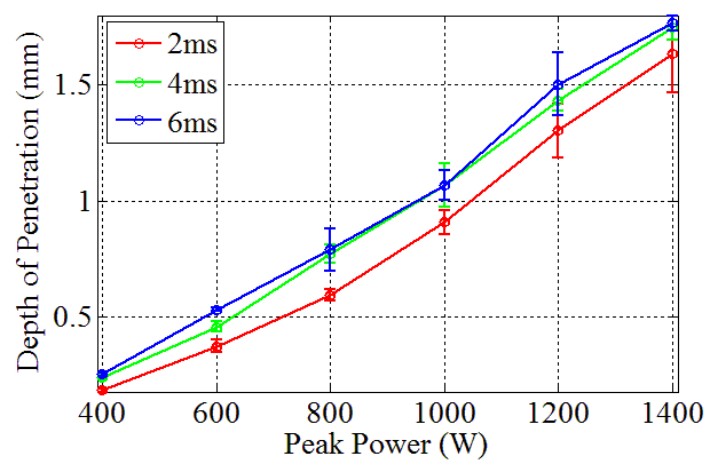

(c)

Figure 3. Depth of penetration from the variation of peak power with focal length of (a) $-5 \mathrm{~mm}$ defocused (b) $0 \mathrm{~mm}$ focused (c) $+5 \mathrm{~mm}$ defocused. 


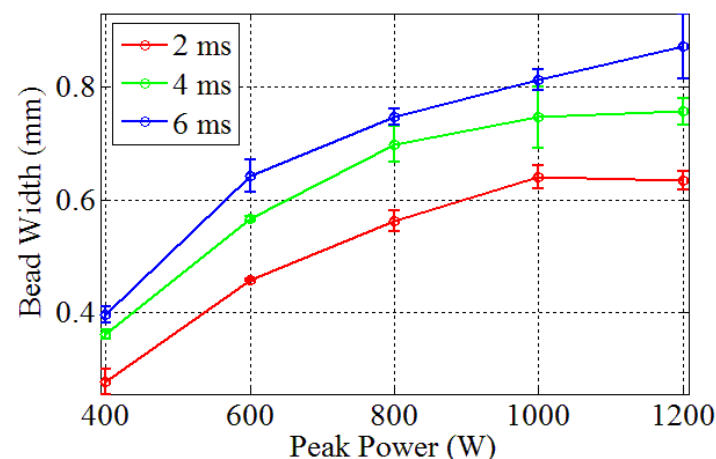

(a)

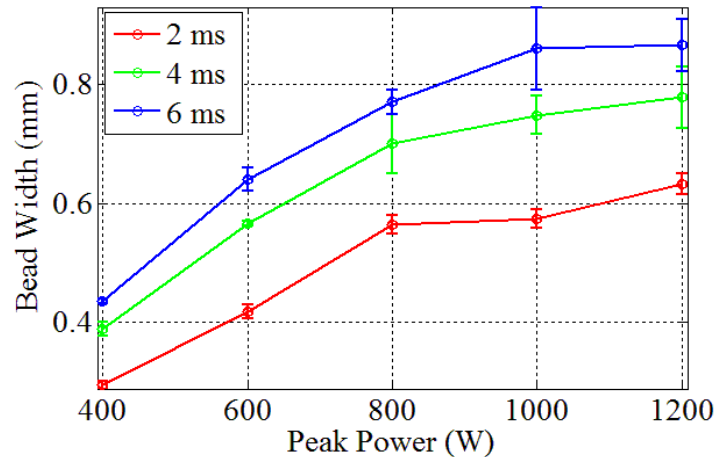

(b)

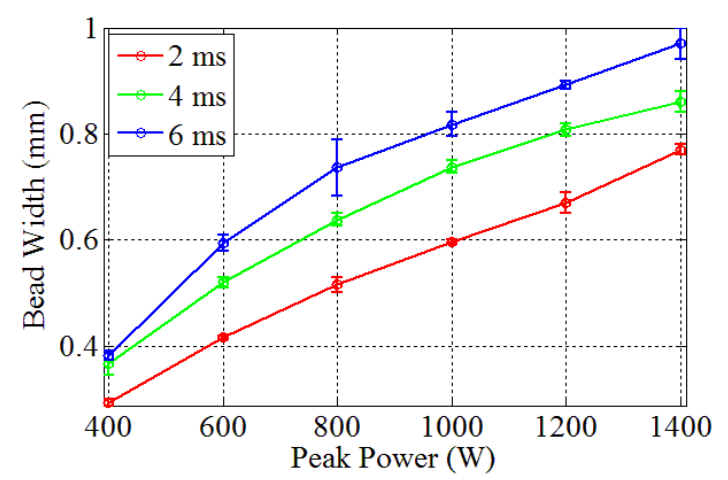

(c)

Figure 4. Bead width from the variation of peak power with defocused focal length of (a) $-5 \mathrm{~mm}$, (b) $0 \mathrm{~mm}$ and; (c) $+5 \mathrm{~mm}$.

According to such trend, it could be said that the aspect ratio started to go over 1 when the peak power reached $800 \mathrm{~W}$. This could be generally observed in all cases of focal length. Based on this trend, it could be concluded that the mode of welding started to change from conduction to keyhole mode at the peak power of $800 \mathrm{~W}$ owing to the other findings [30]. It showed that the keyhole mode welding started to occur when the aspect ratio was more than 1 . Basically, deeper penetration with smaller weld width could be achieved from the keyhole mode laser welding [31] which could explain the trend in these results.

Meanwhile, as the depth of penetration from the different focal lengths was observed (Figure 6), it was found that the highest penetration was recorded at the $0 \mathrm{~mm}$ (focus point) focal length. This is due to the large amount of energy density and heat input given by the laser beam as reported in previous studies [2, 26, 27]. Comparing the process with positive defocused and negative defocused focal length led to the finding that weld depth was much higher at negative defocused. According to the previous work reported by Li et al. [27], at negative defocused, the heat input efficiency was higher and affected weld geometry. This might be the reason why the results showed higher penetration depth at negative defocused point. On the other hand, the trend was quite unclear for the case of peak power $800 \mathrm{~W}$ and below. This was due to the different weld mode as previously explained. 


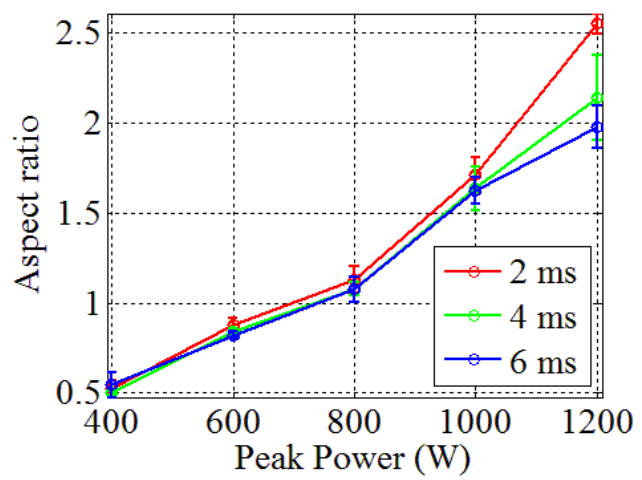

(a)

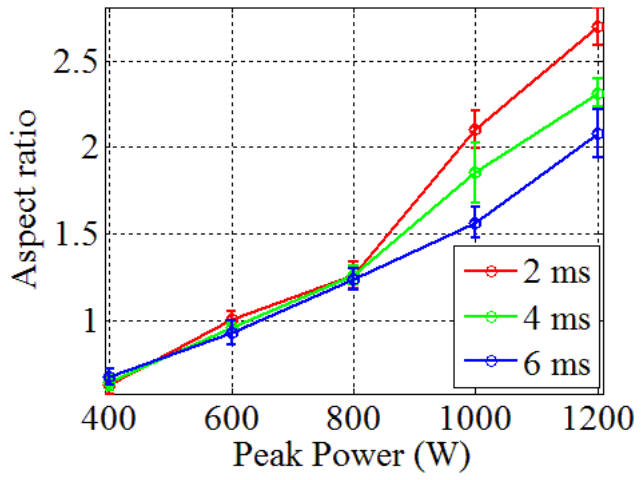

(b)

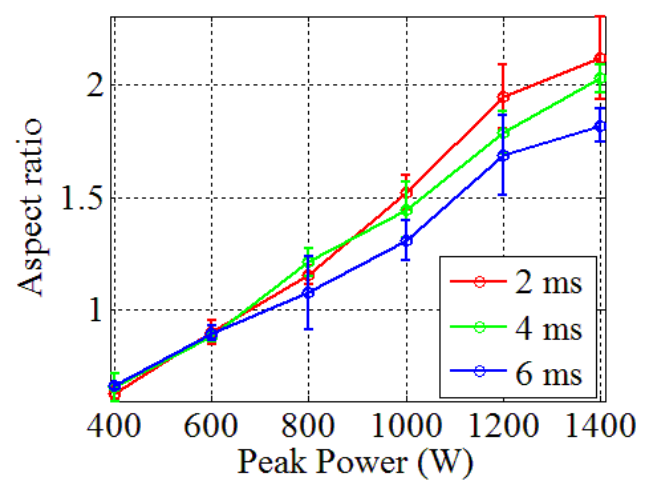

(c)

Figure 5. Aspect ratio variations from the different pulse width at defocused focal length of (a) $-5 \mathrm{~mm}$ (b) $0 \mathrm{~mm}$ and; (c) $+5 \mathrm{~mm}$.

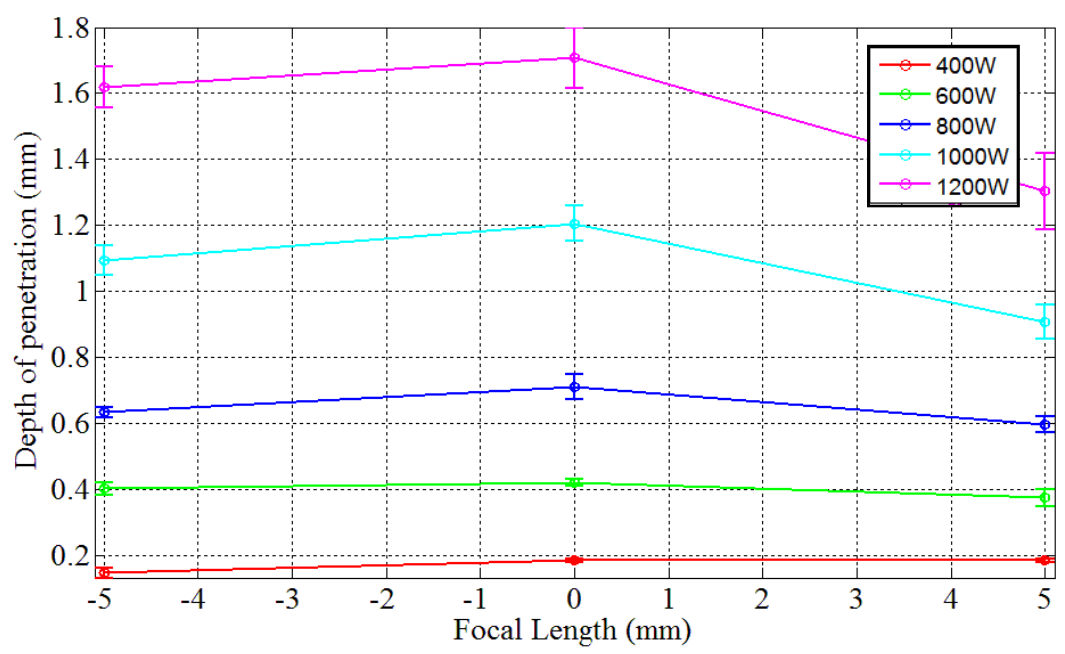

(a) 


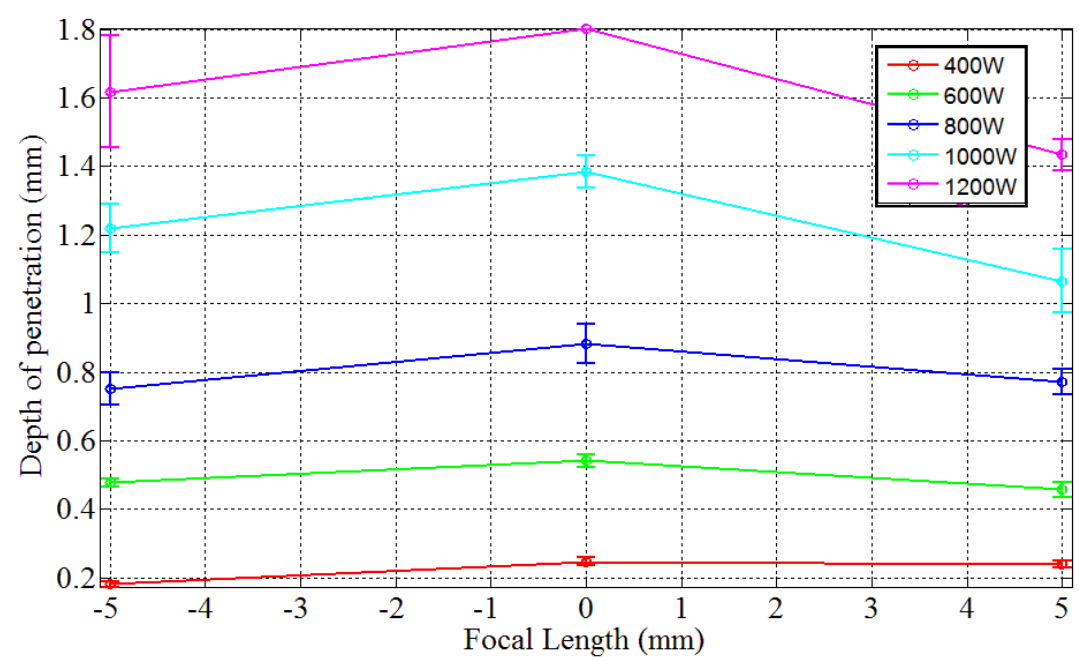

(b)

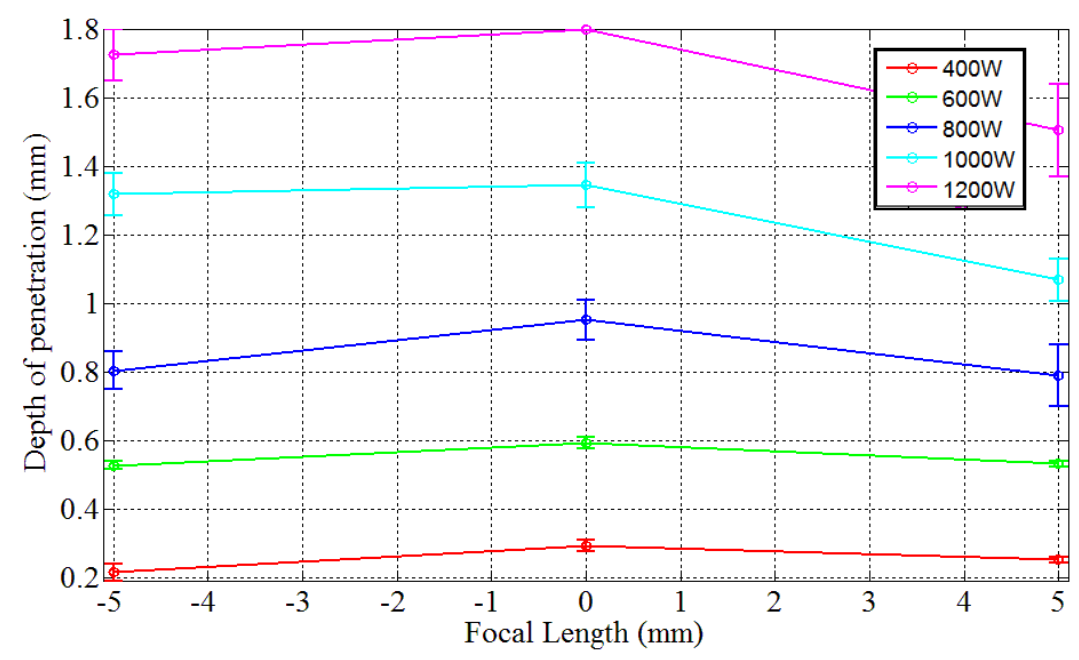

(c)

Figure 6. Weld penetration from the variation of focal length at pulse width of (a) $2 \mathrm{~ms}$, (b) $4 \mathrm{~ms}$ and; (c) $6 \mathrm{~ms}$.

\section{Statistical Trend of Sound Amplitudes with Respect to Weld Geometry}

Several statistical features representing both the dispersion and shape of the amplitude distribution were extracted from the acquired sound. The main reason of this process was to understand how welding parameters affect the behaviour of sound by means of these statistical features, as well as identifying the features giving strong correlations with weld geometry.

In this work, standard deviation, interdecile range and mean absolute deviation were used to represent the dispersion of sound amplitude distribution. Meanwhile, kurtosis, L-scale (L-Cv) and L-kurtosis represented the shape of amplitude distribution. As previously emphasised, both L-scale and L-kurtosis were governed to overcome problems associated with the influence of sample variation and local extreme or outliers. This has been verified in another discipline of studies [23-25]. Therefore, in order to measure the significance of both L-statistic features in characterising the weld geometry, the correlation between those features in Eq. (1) to (6) with the weld geometry is 
presented in this section. For this purpose, linear regression analysis was done for all features and the correlation strength was discussed by means of R-squared value.

At first sight, the trends of all features from the different focal lengths were observed. As illustrated in Figure 7(a), in the case of $-5 \mathrm{~mm}$ defocused and $2 \mathrm{~ms}$ pulse width, the trend for all statistical features showed linear behaviour until the peak power reached $800 \mathrm{~W}$. However, the trend then fluctuated without a clear pattern with the incremental peak power. Conversely, as depicted in Figure 7(b), the pattern of all statistical features showed a slightly flat rate of change with the change in peak power instead of fluctuating like in the case of the $2 \mathrm{~ms}$ pulse width. Meanwhile, the trend of statistical features in the case of $6 \mathrm{~ms}$ pulse width in Figure 7(c) recorded a fluctuating trend as early as the peak power reaching $600 \mathrm{~W}$. In the case of $0 \mathrm{~mm}$ focal length and by disregarding the trend of kurtosis, the trend of the other five statistical features was either fluctuating or decreasing after the peak power exceeded $800 \mathrm{~W}$. This could be observed in the case of different pulse widths from Figure 8(a) to Figure 8(c). Unlike the other cases, the trend recorded for the focal length $+5 \mathrm{~mm}$ as depicted in Figure 9 (a) to Figure (c) was different. It was found that the trend for standard deviation, interdecile range, mean absolute deviation, $\mathrm{L}-\mathrm{Cv}$ and $\mathrm{L}$ - kurtosis still recorded a linear trend even after the peak power reached $800 \mathrm{~W}$. However, the rate of change for these features was quite slow as compared to the trend below $800 \mathrm{~W}$ peak power.

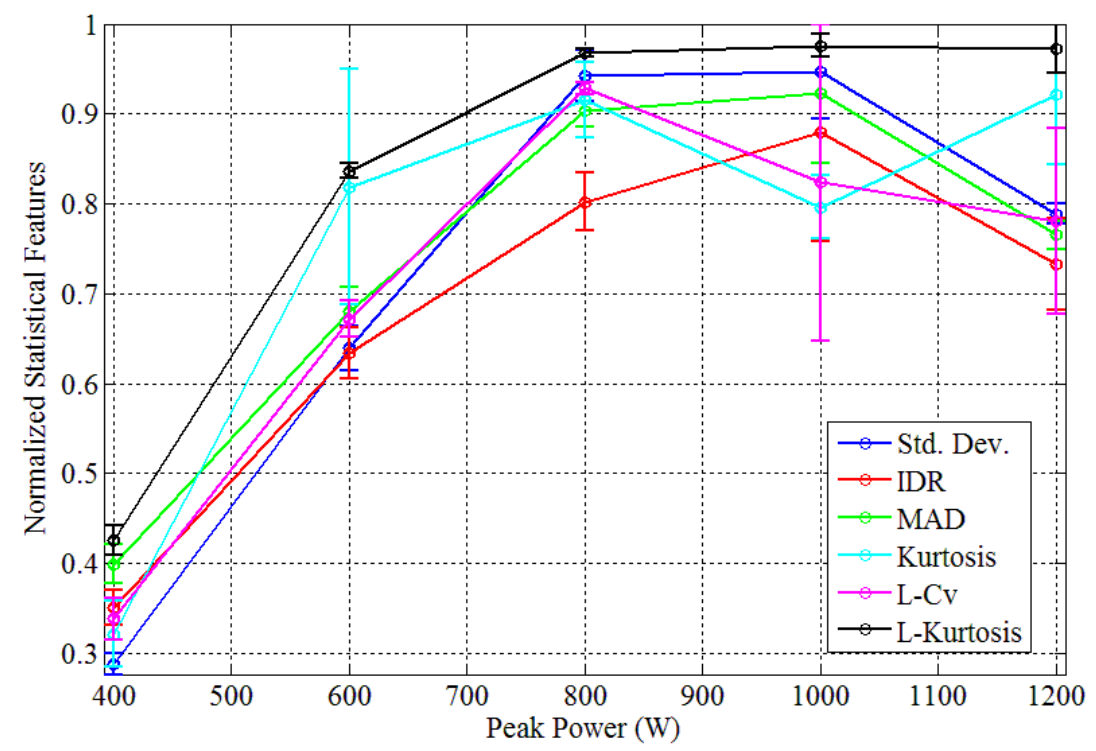

(a) 


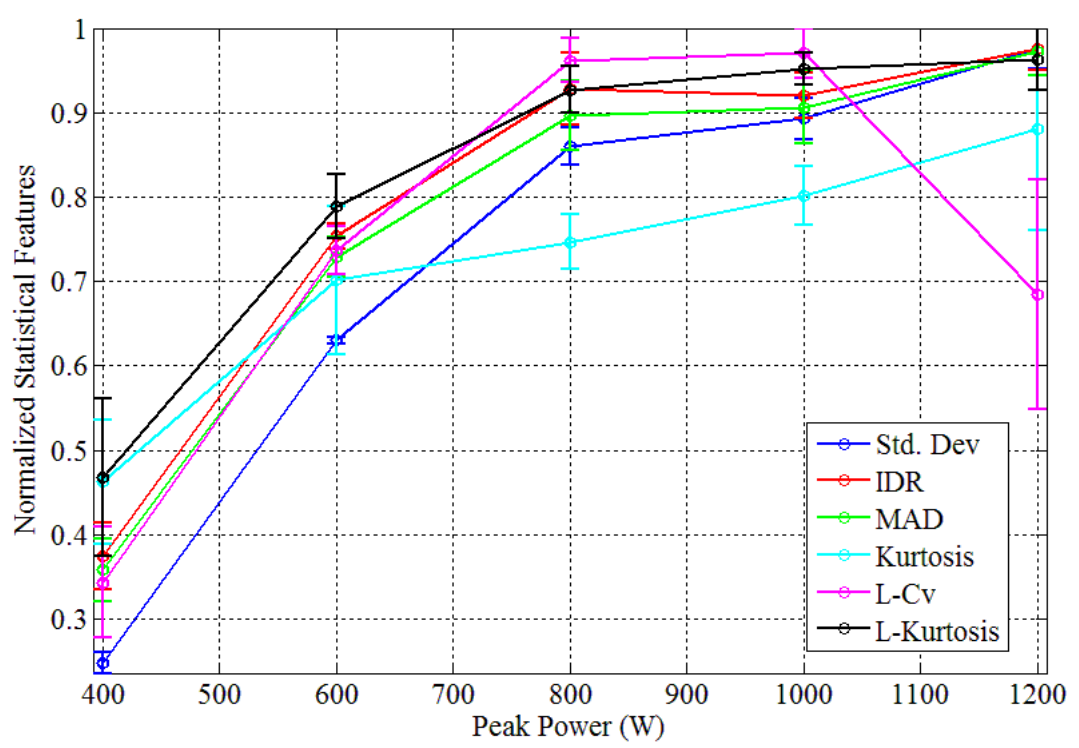

(b)

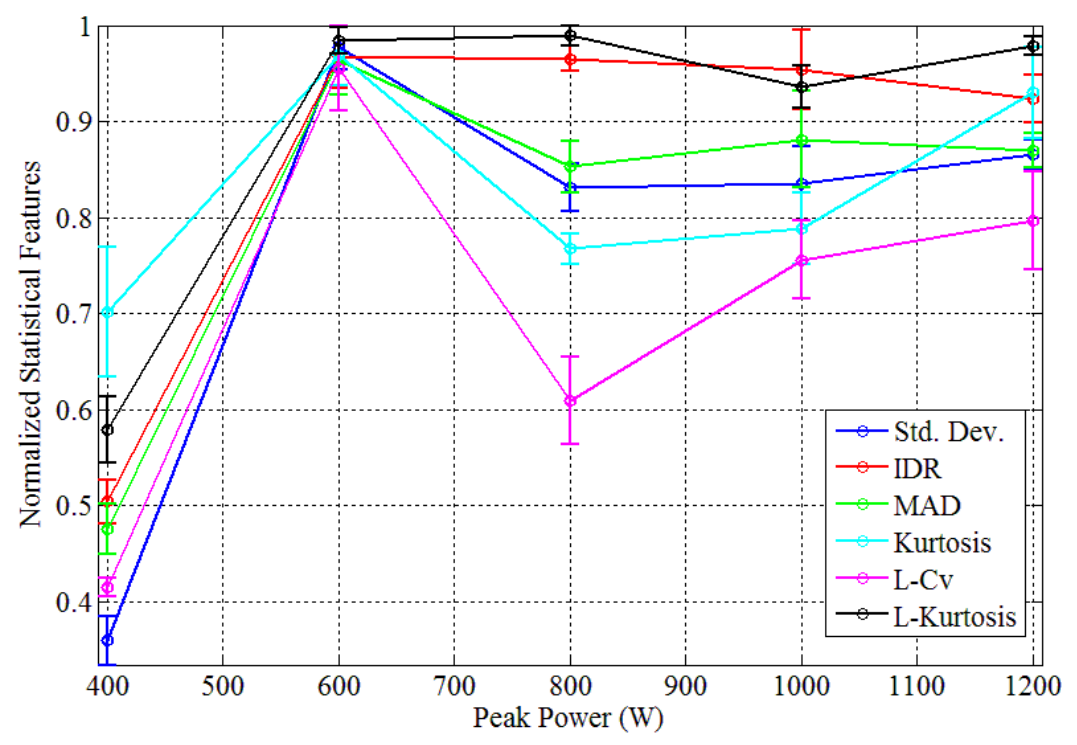

(c)

Figure 7. Statistical features variation with respect to the change in peak power value for- $5 \mathrm{~mm}$ defocused focal length and pulse width of (a) $2 \mathrm{~ms}$, (b) $4 \mathrm{~ms}$ and; (c) $6 \mathrm{~ms}$.

To summarise the results from Figures 7 to 9, it could be said that there were variations in the trends of all statistical features when the peak power reached $800 \mathrm{~W}$. The recorded trends were either decreasing or fluctuating accordingly, which could be found for almost all cases of focal length and pulse width. As previously discussed, the trend of aspect ratio in Figure 5 shows a mode transition from conduction to keyhole welding as the peak power exceeded $800 \mathrm{~W}$. As explained by $[32,33]$ in their works, keyhole mode laser welding was often unstable due to many factors contributing to it. This included the dynamics of weld pool and plasma plume. As sound is mainly generated from the dynamic behaviour of plasma plume [9,34], this might explain the unstable trend for the statistical features of sound at the keyhole mode region. Meanwhile, the trend was more stable despite the small rate of change in the case of $+5 \mathrm{~mm}$ focal length. This might be 
due to the smaller aspect ratio, whereas the bead width was larger in this case. As the keyhole width was larger, the laser energy absorption process was more stable, which might reduce the instability inside the keyhole. As shown in Figure 10, a smaller aspect ratio was recorded for all different pulse widths in the case of $+5 \mathrm{~mm}$ defocused.

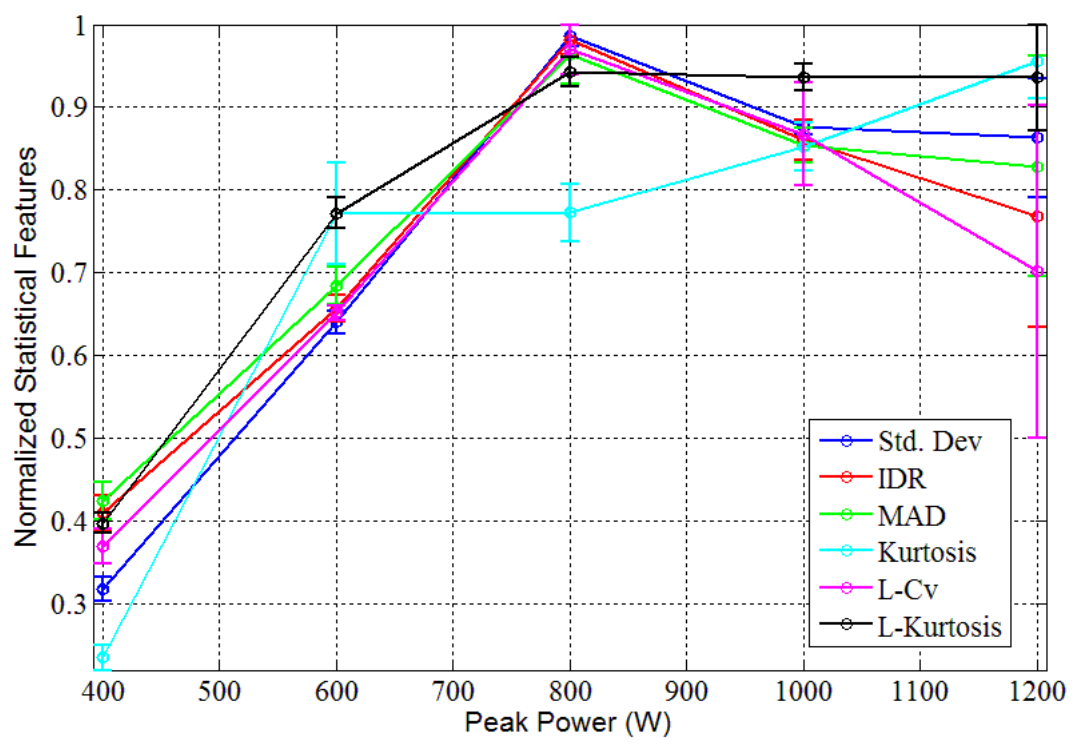

(a)

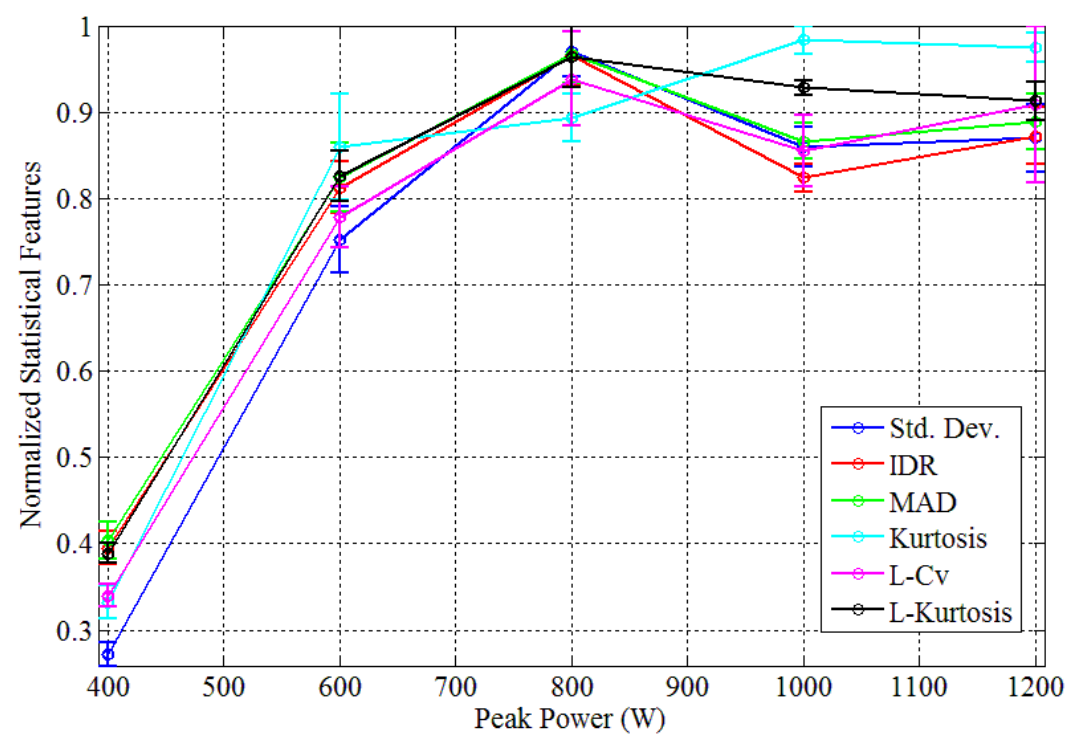

(b) 


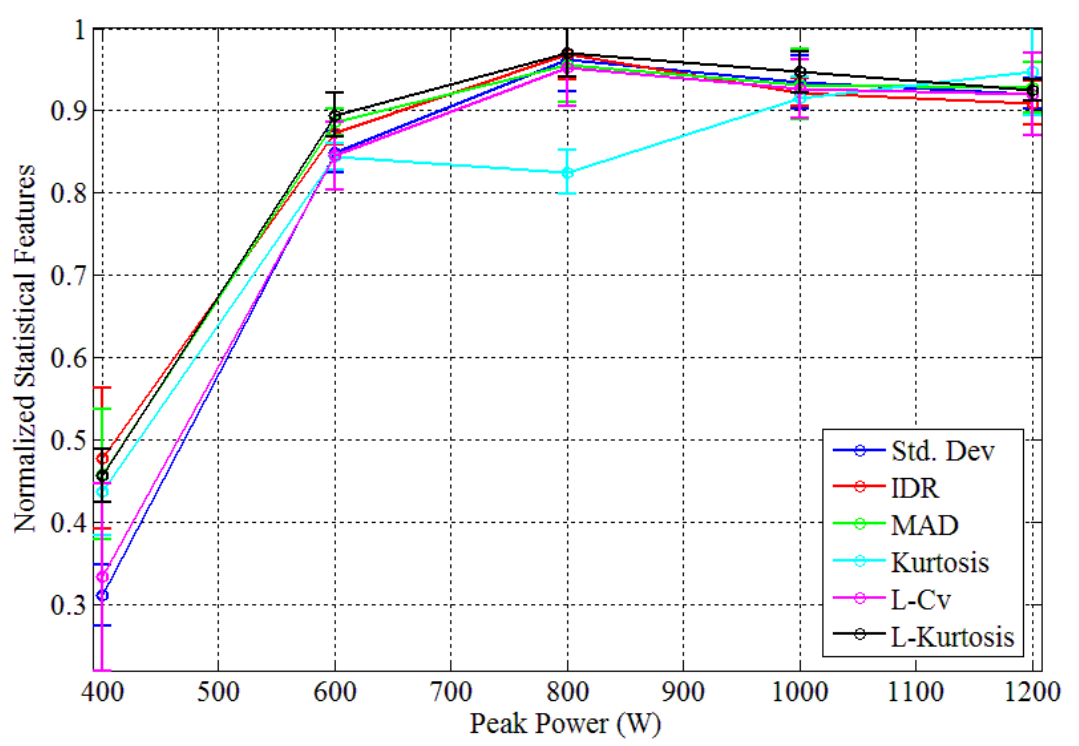

(c)

Figure 8. Statistical features variation with respect to the change in peak power at $0 \mathrm{~mm}$ focus point and pulse width of (a) $2 \mathrm{~ms}$, (b) $4 \mathrm{~ms}$ and; (c) $6 \mathrm{~ms}$.

In the previously reported results, the statistical features of the sound amplitude distribution showed a significant pattern with respect to the change in peak power at the focal length of $+5 \mathrm{~mm}$. Hence, in the next step of the analysis, the statistical features of the acquired sound signal from the test set with focal length of $+5 \mathrm{~mm}$ were selected for the correlation analysis. Moreover, due to the different physical behaviours occurring during varying modes of welding, only the signal from the keyhole mode region was selected in this part of analysis. It was previously underlined that the correlation analysis was done to study the trend of statistical features in response to the change in weld geometry. Moreover, it was also important to identify which statistical feature was yielding a significant correlation with the weld geometry.

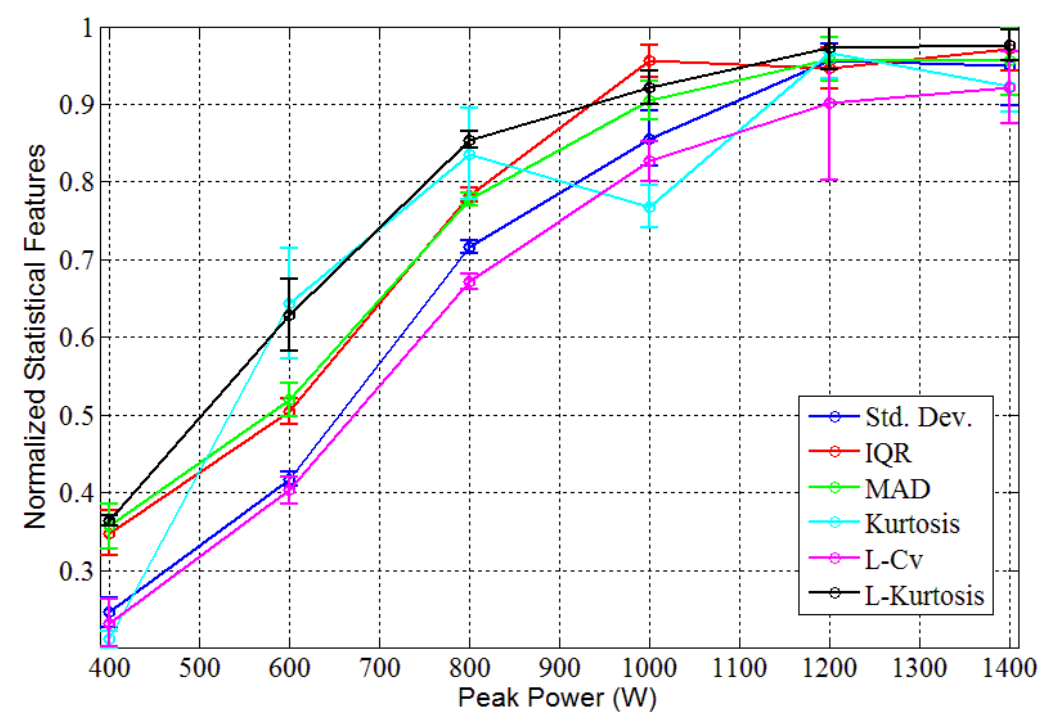

(a) 


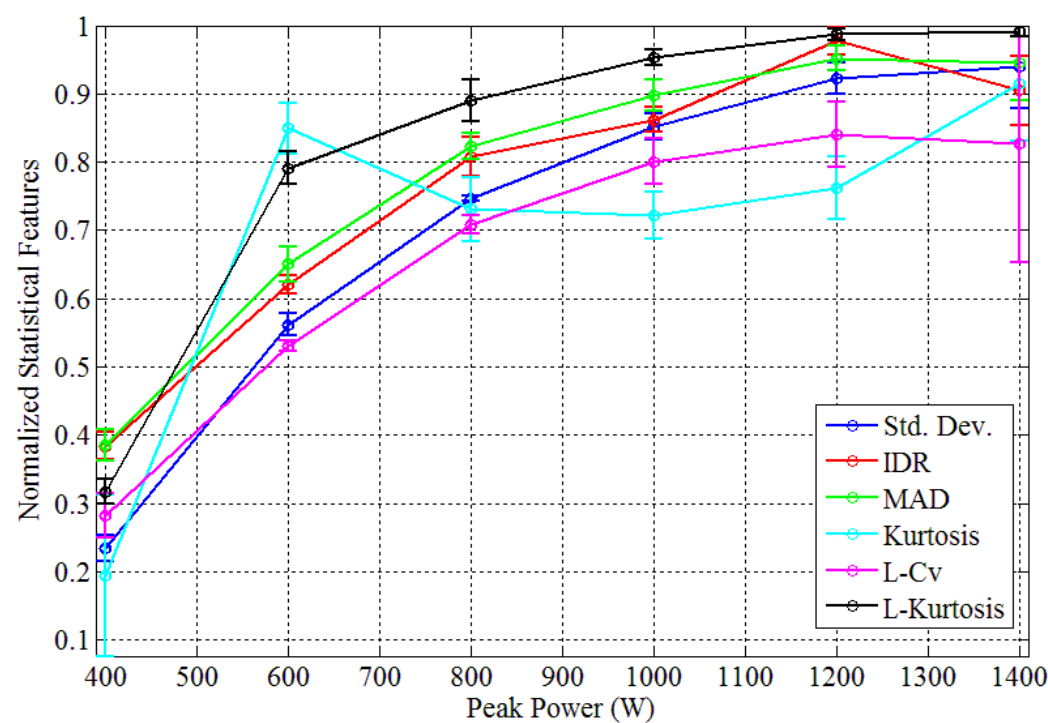

(b)

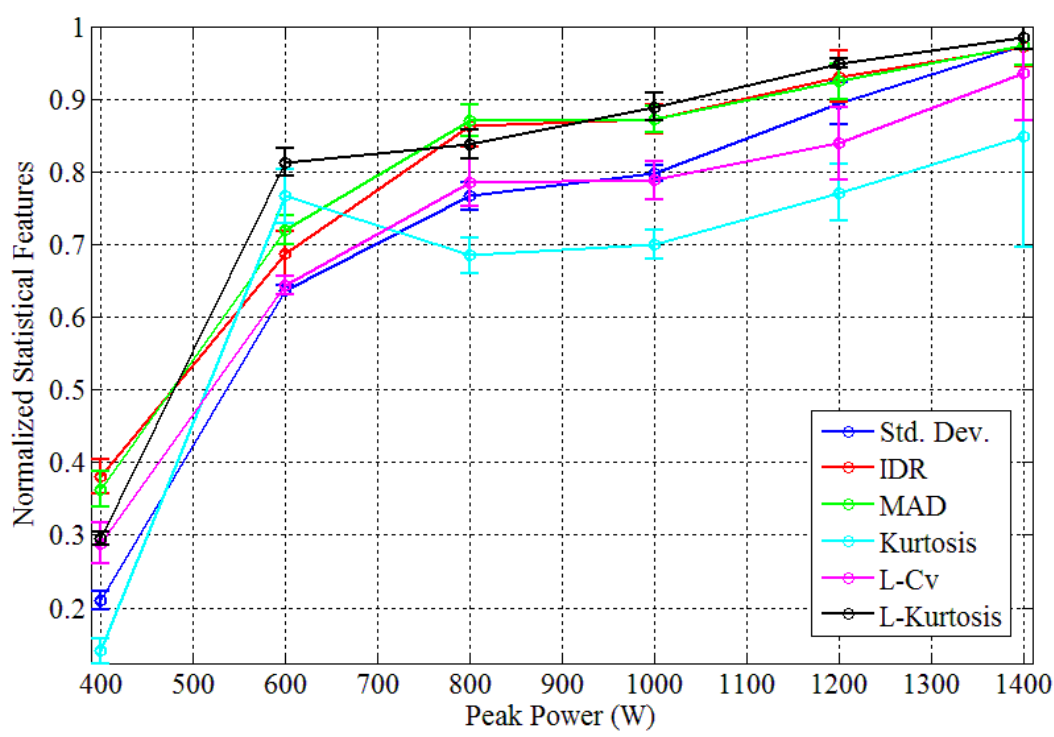

(c)

Figure 9. Statistical features variation with respect to the change in peak power at +5 mm defocused focal length and pulse width of (a) $2 \mathrm{~ms}$, (b) $4 \mathrm{~ms}$ and; (c) $6 \mathrm{~ms}$.

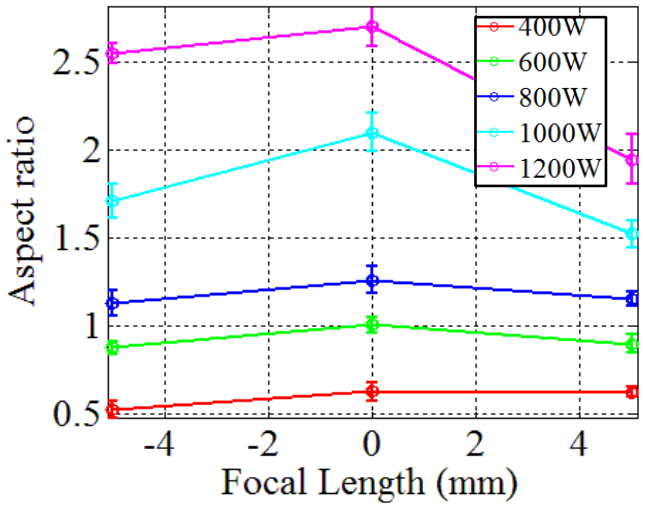

(a)

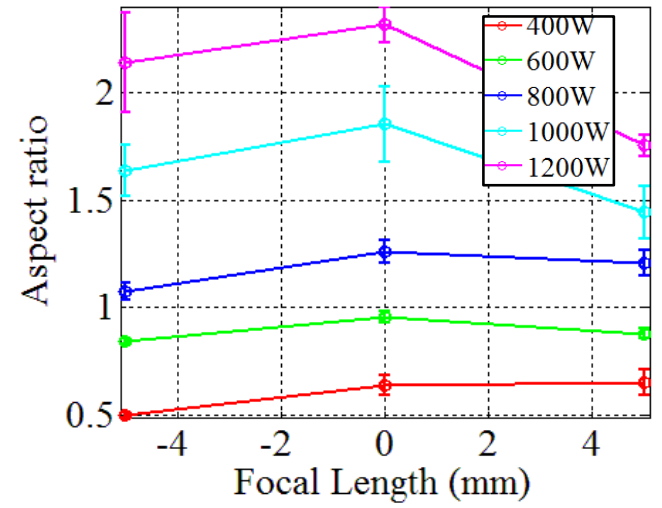

(b) 


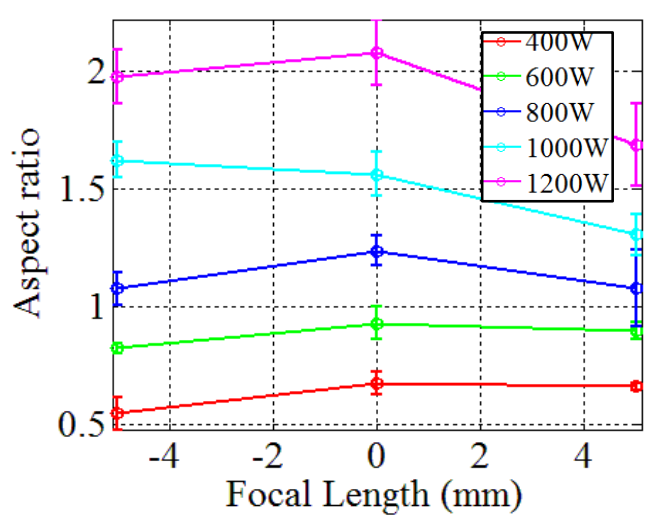

(c)

Figure 10. Aspect ratio variation from different focal length and pulse width of (a) $2 \mathrm{~ms}$, (b) $4 \mathrm{~ms}$ and; (c) $6 \mathrm{~ms}$.

Therefore, the correlations between standard deviation, interdecile range, mean absolute deviation, kurtosis, L-Cv (scale), and L-kurtosis with the weld geometry were measured using the R-squared values obtained from the regression analysis. Table 2 shows the R-squared values for the correlation between all six statistical features with the weld penetration. According to Table 2, it was clear that only standard deviation and Lkurtosis recorded good correlation with the weld penetration, with R-squared values more than $80 \%$ for all three different levels of pulse width. In contrast, features, such as interdecile range, mean absolute deviation, kurtosis and L-cv seemed unsuitable to be used in characterising the weld depth in this study. Comparing between the R-squared values of standard deviation and L-kurtosis, it was noted that in most cases, L-kurtosis recorded higher R-squared values. Standard deviation showed the highest value only for the case of welding process, with the 2 ms pulse width.

Table 2. R-Square values for correlation between statistical features of sound amplitude with the weld depth.

\begin{tabular}{lccc}
\hline \multirow{2}{*}{ Statistical Features } & \multicolumn{3}{c}{ R-Squares Values } \\
\cline { 2 - 4 } & $2 \mathrm{~ms}$ & $4 \mathrm{~ms}$ & $6 \mathrm{~ms}$ \\
\hline Standard Deviation & 0.9625 & 0.8233 & 0.8609 \\
Interdecile Range & 0.6115 & 0.5028 & 0.7098 \\
Mean Absolute Deviation & 0.7186 & 0.6781 & 0.6690 \\
Kurtosis & 0.3803 & 0.5944 & 0.6717 \\
L-Cv & 0.7148 & 0.1480 & 0.5579 \\
L-Kurtosis & 0.9146 & 0.9391 & 0.9390 \\
\hline
\end{tabular}

In order to investigate further, the correlation plot for both standard deviation and L-kurtosis with the depth of penetration is illustrated in Figure 11 and Figure 12, respectively. Based on the plot in Figure 11(a) and Figure 12(a), the deviation for both statistical features was quite large at penetration above $1.2 \mathrm{~mm}$. However, the deviation size was slightly similar, which might cause a small difference between the R-squared values of both statistical parameters. In the case of $4 \mathrm{~ms}$ and $6 \mathrm{~ms}$ pulse width, the deviation of L-kurtosis in Figure 12(b) and Figure 12(c) is smaller compared to the standard deviation in Figure 11(b) and Figure 11(c). This trend explained why the Rsquared value for L-kurtosis was much larger compared to the standard deviation. 


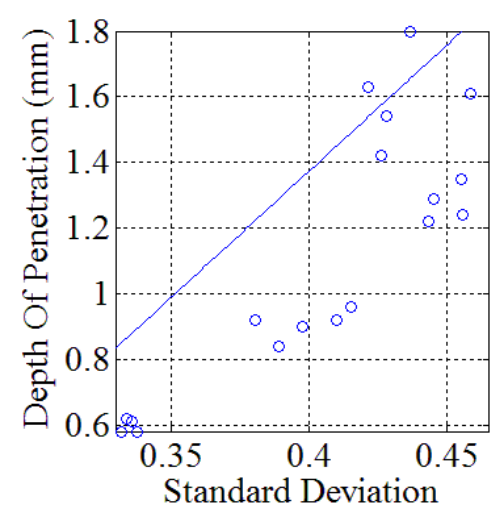

(a)

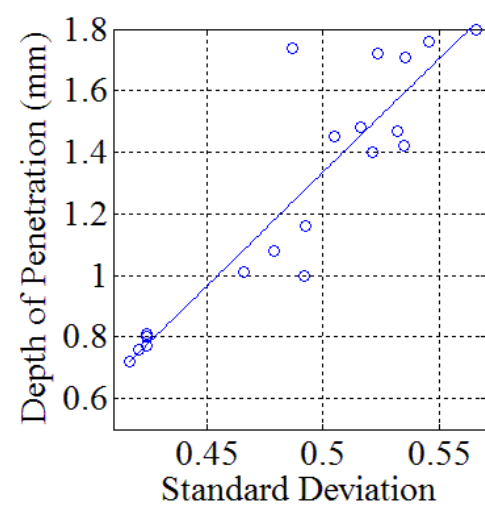

(b)

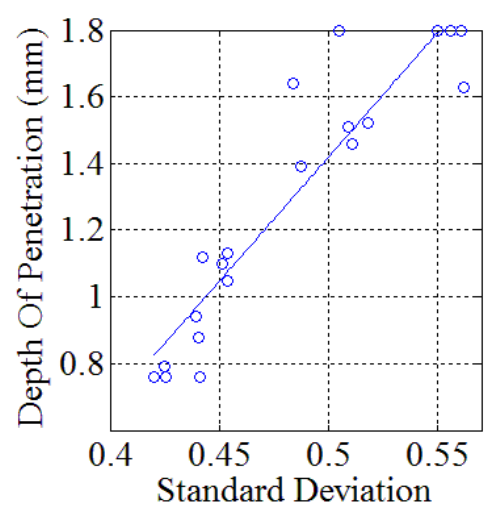

(c)

Figure 11. Relation between standard deviation of sound amplitudes and depth of penetration during welding process at $+5 \mathrm{~mm}$ defocused focal length and pulse width of (a) $2 \mathrm{~ms}$, (b) $4 \mathrm{~ms}$ and; (c) $6 \mathrm{~ms}$.

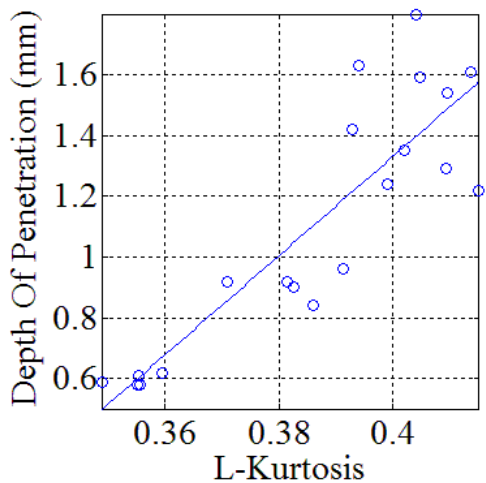

(a)

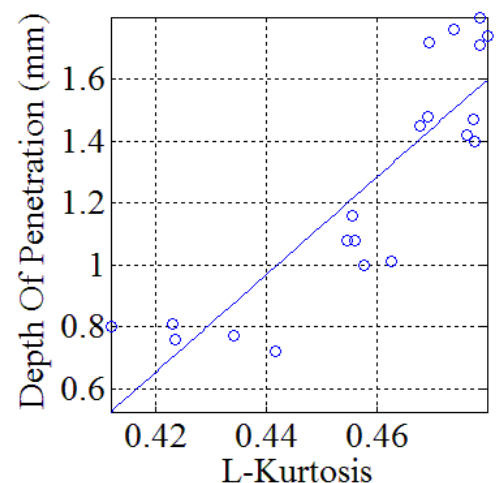

(b)

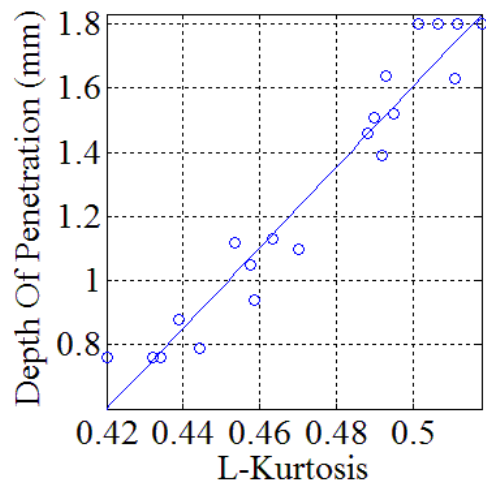

(c)

Figure 12. Relation between L-Kurtosis of sound amplitudes and depth of penetration during welding process at $+5 \mathrm{~mm}$ defocused focal length and pulse width of (a) $2 \mathrm{~ms}$,

(b) $4 \mathrm{~ms}$ and; (c) $6 \mathrm{~ms}$.

Meanwhile, an observation for the R-squared values in Table 3 shows that the correlation between all six statistical features and the width of weld bead is slightly similar with the trend reported in Table 2. Based on the R-squared values, the L-kurtosis shows the highest value compared to the other five statistical features. Moreover, the plot of standard deviation in Figure 13 and L-kurtosis in Figure 14 further proves that the deviation of L-kurtosis values from the regression line is smaller, resulting in higher Rsquared value. This illustrates that the L-kurtosis not only could characterise the weld penetration, but also the width of the weld bead. 
Table 3. R-Square values for correlation between statistical features of sound amplitude with weld bead width.

\begin{tabular}{lccc}
\hline \multirow{2}{*}{ Statistical Features } & \multicolumn{3}{c}{ R-Squares Values } \\
\cline { 2 - 4 } & $2 \mathrm{~ms}$ & $4 \mathrm{~ms}$ & $6 \mathrm{~ms}$ \\
\hline Standard deviation & 0.7405 & 0.8676 & 0.7977 \\
Interdecile range & 0.6131 & 0.5620 & 0.6439 \\
Mean absolute deviation & 0.6949 & 0.7307 & 0.6093 \\
Kurtosis & 0.3346 & 0.4945 & 0.5935 \\
L-Cv & 0.7549 & 0.1955 & 0.5118 \\
L-kurtosis & 0.9897 & 0.9950 & 0.8941 \\
\hline
\end{tabular}

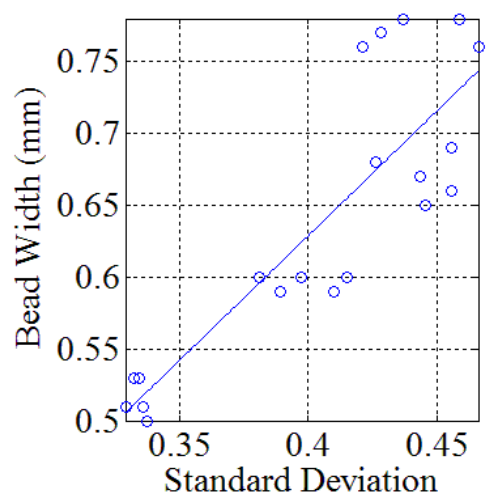

(a)

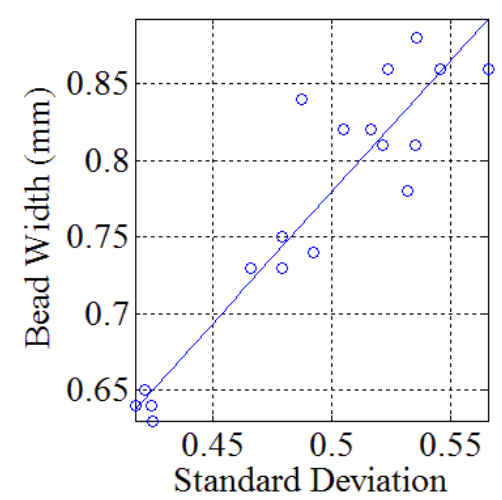

(b)

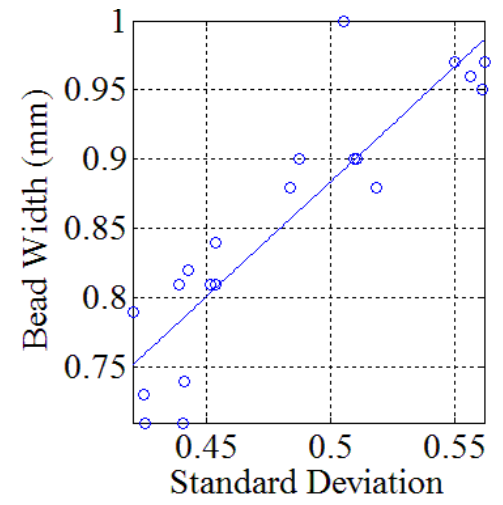

(c)

Figure 13. Relation between standard deviation of sound amplitudes and bead width during welding process at $+5 \mathrm{~mm}$ defocused focal length and pulse width of (a) $2 \mathrm{~ms}$, (b) $4 \mathrm{~ms}$ and; (c) $6 \mathrm{~ms}$.

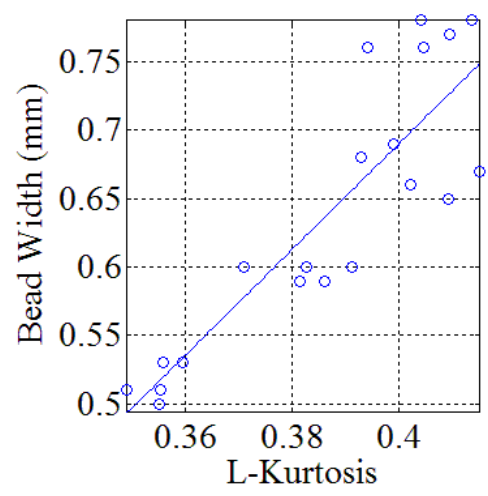

(a)

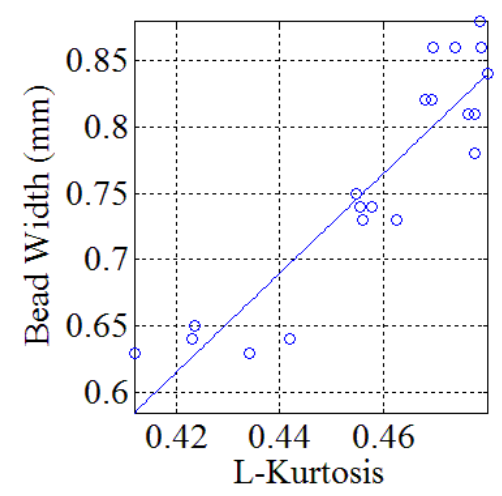

(b)

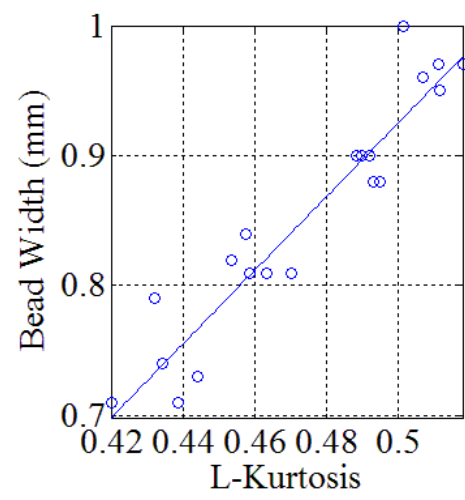

(c)

Figure 14. Relation between L-Kurtosis of sound amplitudes and bead width during welding process at $+5 \mathrm{~mm}$ defocused focal length and pulse width of (a) $2 \mathrm{~ms}$, (b) $4 \mathrm{~ms}$ and; (c) 6 ms.

\section{CONCLUSION}

In this work, the correlation between the trends for statistical features of sound amplitude distribution with respect to the change in weld geometry during pulse mode laser welding was successfully studied. According to the results from all tests and analysis, it could be 
summarised that the trend of statistical features for the sound amplitude distribution varies at different test sets and focal length. The inclination is influenced by the stability of the process during keyhole mode in which the higher aspect ratio gives an unstable process, leading to the non-linear trend of the statistical features. Therefore, the statistical features of sound signal acquired from the test at positive defocused focal length shows a good correlation with the weld parameters and weld geometry. More specifically, standard deviation and L-kurtosis reveals good correlation with both weld depth and bead width. Comparing both statistical features shows that the L-kurtosis is able to characterise weld geometry better than the standard deviation.

The correlation between the statistical features of sound amplitude and weld geometry during pulse mode laser welding was successfully studied. The L-statistical features were further identified to show a higher degree of correlation with the weld geometry compared to other common statistical features. It is expected that the findings in this study could contribute to the development of online monitoring system, which would benefit from the information on weld geometry during the welding process in future.

\section{ACKNOWLEDGEMENT}

The authors would like to thank Universiti Malaysia Pahang for laboratory facilities and financial assistance under PGRS180318 Postgraduates Research Scheme.

\section{REFERENCES}

[1] Dawes C. Laser welding a practical guide. United Kingdom: Abington Publishing; 2008.

[2] Benyounis K, Olabi A-G. Optimization of different welding processes using statistical and numerical approaches-A reference guide. Advances in engineering software. 2008;39:483-96.

[3] Pakmanesh M, Shamanian M. Optimization of pulsed laser welding process parameters in order to attain minimum underfill and undercut defects in thin $316 \mathrm{~L}$ stainless steel foils. Optics \& Laser Technology. 2018;99:30-8.

[4] Mostaan H, Shamanian M, Hasani S, Safari M, Szpunar J. Nd: YAG laser microwelding of ultra-thin FeCo-V magnetic alloy: optimization of weld strength. Transactions of Nonferrous Metals Society of China. 2017;27:1735-46.

[5] Zhou L, Luo L, Tan C, Li Z, Song X, Zhao H, et al. Effect of welding speed on microstructural evolution and mechanical properties of laser welded-brazed Al/brass dissimilar joints. Optics \& Laser Technology. 2018;98:234-46.

[6] Nuraini A, Zainal A, Hanim MA. The effects of welding parameters on butt joints using robotic gas metal arc welding. Journal of Mechanical Engineering and Sciences. 2014;6:988-94.

[7] Azhani N, Razak A, Shing Shian N. Investigation of effects of MIG welding on corrosion behaviour of AISI 1010 carbon steel. Journal of Mechanical Engineering and Sciences. 2014;75:1168-78.

[8] Ghazali FA, Manurung YHP, Mohamed MA, Alias SK, Abdullah S. Effect of process parameters on the mechanical properties and failure behavior of spot welded low carbon steel. Journal of Mechanical Engineering and Sciences. 2015;8:1489-97. 
[9] Hoffman J, Szymanski Z, Jakubowski J, Kolasa A. Analysis of acoustic and optical signals used as a basis for controlling laser-welding processes. Welding International. 2002;16:18-25.

[10] Huang W, Kovacevic R. Feasibility study of using acoustic signals for online monitoring of the depth of weld in the laser welding of high-strength steels. Proceedings of the Institution of Mechanical Engineers, Part B: Journal of Engineering Manufacture. 2009;223:343-61.

[11] Luo Z, Liu W, Wang Z, Ao S. Monitoring of laser welding using source localization and tracking processing by microphone array. The International Journal of Advanced Manufacturing Technology. 2016;86:21-8.

[12] Ao S, Luo Z, Feng M, Yan F. Simulation and experimental analysis of acoustic signal characteristics in laser welding. The International Journal of Advanced Manufacturing Technology. 2015;81:277-87.

[13] Duley WW, Mao YL. The effect of surface condition on acoustic emission during welding of aluminium with CO 2 laser radiation. Journal of Physics D: Applied Physics. 1994;27:1379.

[14] Farson D, Hillsley K, Sames J, Young R. Frequency-time characteristics of airborne signals from laser welds. Journal of Laser Applications. 1996;8:33-42.

[15] Huang W, Kovacevic R. A neural network and multiple regression method for the characterization of the depth of weld penetration in laser welding based on acoustic signatures. Journal of Intelligent Manufacturing. 2009;22:131-43.

[16] Farson D, Ali A, SANG Y. Relationship of optical and acoustic emissions to laser weld penetration. Welding Journal. 1998;77:142. s-8. s.

[17] Farson D, Ali A, Li X. Laser weld penetration monitoring with multiple emission signal measurements. Journal of Laser Applications. 1999;11:47-53.

[18] Zhang Z, Chen H, Xu Y, Zhong J, Lv N, Chen S. Multisensor-based real-time quality monitoring by means of feature extraction, selection and modeling for $\mathrm{Al}$ alloy in arc welding. Mechanical Systems and Signal Processing. 2015;6061:151-65.

[19] Grad L, Grum J, Polajnar I, Marko Slabe J. Feasibility study of acoustic signals for on-line monitoring in short circuit gas metal arc welding. International Journal of Machine Tools and Manufacture. 2004;44:555-61.

[20] Pal K, Bhattacharya S, Pal SK. Investigation on arc sound and metal transfer modes for on-line monitoring in pulsed gas metal arc welding. Journal of Materials Processing Technology. 2010;210:1397-410.

[21] Pal K, Bhattacharya S, Pal SK. Prediction of metal deposition from arc sound and weld temperature signatures in pulsed MIG welding. The International Journal of Advanced Manufacturing Technology. 2009;45:1113.

[22] Fidali M. Detection of welding process instabilities using acoustic signals. In: Timofiejczuk A, Łazarz BE, Chaari F, Burdzik R, editors. Advances in Technical Diagnostics. Cham: Springer International Publishing; 2018. p. 191-201.

[23] Adamowski K. Regional analysis of annual maximum and partial duration flood data by nonparametric and L-moment methods. Journal of Hydrology. 2000;229:219-31.

[24] González J, Valdés JB. A regional monthly precipitation simulation model based on an L-moment smoothed statistical regionalization approach. Journal of Hydrology. 2008;348:27-39.

[25] Ouarda TBMJ, Charron C, Chebana F. Review of criteria for the selection of probability distributions for wind speed data and introduction of the moment and 
L-moment ratio diagram methods, with a case study. Energy Conversion and Management. 2016;124:247-65.

[26] Assuncao E, Williams S. Comparison of continuous wave and pulsed wave laser welding effects. Optics and Lasers in Engineering. 2013;51:674-80.

[27] Li S, Chen G, Zhou C. Effects of welding parameters on weld geometry during high-power laser welding of thick plate. The International Journal of Advanced Manufacturing Technology. 2015;79:177-82.

[28] Hosking JRM. Moments or L moments? An example comparing two measures of distributional shape. The American Statistician. 1992;46:186-9.

[29] Zielinski R. L-Statistics as non parametric quantile estimators. Institute of Mathematics Polish Academy of Sciences. 2005.

[30] Nakamura S, Sakurai M, Kamimuki K, Inoue T, Ito Y. Detection technique for transition between deep penetration mode and shallow penetration mode in $\mathrm{CO} 2$ laser welding of metals. Journal of Physics D: Applied Physics. 2000;33:2941.

[31] Ready JF, Farson DF. LIA handbook of laser materials processing: Laser Institute of America Orlando; 2001.

[32] Kawahito Y, Mizutani M, Katayama S. High quality welding of stainless steel with $10 \mathrm{~kW}$ high power fibre laser. Science and Technology of Welding and Joining. 2009;14:288-94.

[33] Wahba M, Mizutani M, Kawahito Y, Katayama S. Keyhole stability in disc laser welding of AZ31B and AZ61A magnesium alloys and weld metal properties. Science and Technology of Welding and Joining. 2010;15:559-66.

[34] Szymanski Z, Hoffman J, Kurzyna J. Plasma plume oscillations during welding of thin metal sheets with a CW CO 2 laser. Journal of Physics D: Applied Physics. 2001;34:189. 